\title{
Assessment of Different Dimensions of Shame Proneness: Validation of the SHAME
}

Assessment

2020, Vol. 27(8) 1699-1717

(C) The Author(s) 2018

Article reuse guidelines:

sagepub.com/journals-permissions DOI: $10.1177 / 1073191118820130$

journals.sagepub.com/home/asm

@SAGE

\author{
Corinna N. Scheel', Hedwig Eisenbarth' ${ }^{2}$, \\ and Katrin Rentzsch ${ }^{3}$
}

\begin{abstract}
A large body of research revealed that shame is associated with adaptive and maladaptive correlates. The aim of this work was to validate a new dimensional instrument (SHAME), which was developed to disentangle adaptive and maladaptive dimensions of shame proneness. Confirmatory factor analyses supported the three-factorial structure (bodily, cognitive, and existential shame) in American $(n=502)$ and German $(n=496)$ community samples, using invariance testing. Bifactor model analyses exhibited distinct associations of adaptive (bodily and cognitive shame) and maladaptive (existential shame) dimensions of shame with psychopathology and social functioning. Network analyses highlighted the role of existential shame in psychopathology, especially for a clinical sample of patients with Borderline Personality Disorder $(n=92)$. By placing shame pronenesss into a network of similar and dissimilar constructs, the current findings serve as a foundation for drawing conclusions about the adaptive and maladaptive nature of shame.
\end{abstract}

\section{Keywords}

shame, self-conscious emotions, validity, factor structure, invariance, psychopathology, mental health

The past decades have seen a growing trend in research on shame and different assessments of shame (e.g., Gilbert et al., 2010; Tangney \& Dearing, 2002; Tracy \& Robins, 2006). Shame is a highly aversive self-conscious emotion that is typically evoked after moral transgressions or the experience of incompetence and is accompanied by intense feelings of worthlessness, inferiority, and a damaged selfimage (de Hooge, 2013; de Hooge, Zeelenberg, \& Breugelmans, 2011; Gilbert et al., 2010; M. Lewis, 2008; Tangney, Burggraf, \& Wagner, 1995). Shame has a strong impact on social functioning, as well as on the development and retention of mental disorders. On the one hand, several studies highlight the role of shame in maintaining moral values and social rules (Gausel, Vignoles, \& Leach, 2016; Murphy \& Kiffin-Petersen, 2017; Nazarov et al., 2015). This is further supported by recent studies that have found shame to be linked to empathy toward others (Cohen, Wolf, Panter, \& Insko, 2011), engagement in repairing behaviors (de Hooge, Zeelenberg, \& Breugelmans, 2010), and prosocial motivation (Gausel et al., 2016). On the other hand, it has been shown that shame is also associated with withdrawal from or the breakdown of social relationships (Black, Curran, \& Dyer, 2013; Dorahy et al., 2017). Moreover, shame is associated with fear of relationships (Dorahy et al., 2017), hostility (Scott et al., 2015), and long-term anger reactions (Tangney, Wagner, Hill-Barlow, Marschall, \& Gramzow, 1996), as well as lower self-esteem (Deonna,
Rodogno, \& Teroni, 2012; Iannaccone, D’Olimpio, Cella, \& Cotrufo, 2016) and decreased empathy (Arimitsu, 2006; Joireman, 2004).

From a clinical perspective, shame has been shown to be connected to several psychopathological symptoms such as suicidality (Lester, 1998), psychopathological anger (Tangney et al., 1996), self-inflicted injury (Brown, Linehan, Comtois, Murray, \& Chapman, 2009), depressive mood, as well as mental disorders such as borderline-personality disorder (Rizvi, Brown, Bohus, \& Linehan, 2011; Scheel, Bender, Tuschen-Caffier, \& Jacob, 2013; Scheel et al., 2014), social phobia, major depression, substance abuse, and eating disorders (Goss \& Allan, 2009; Keith, Gillanders, \& Simpson, 2009; Skårderud, 2007).

Taken together, previous research has revealed adaptive and maladaptive outcomes of shame (see Iannaccone et al., 2016; Murphy \& Kiffin-Petersen, 2017; Nazarov et al., 2015; Scott et al., 2015). In the following, we argue that many of the paradoxical findings about shame can be

\footnotetext{
'Central Institute of Mental Health, Heidelberg University, Germany ${ }^{2}$ University of Southampton, Southampton, UK

${ }^{3}$ University of Bamberg, Bamberg, Germany

\section{Corresponding Author:}

Corinna N. Scheel, Institute for Psychiatric and Psychosomatic Psychotherapy, Central Institute of Mental Health, Mannheim, Heidelberg University, J5, Mannheim 68159, Germany.

Email: cnscheel@yahoo.de
} 
resolved by distinguishing between adaptive and maladaptive aspects of shame. Previous research, however, has typically conceptualized shame as a maladaptive construct, especially by focusing on shame-proneness (i.e., the tendency to experience shame). In conformity with the ongoing discussion on transdiagnostic factors for mental health problems and the plea for studying meaningful multidimensional constructs (National Institute of Mental Health's Research Domain Criteria; Cuthbert \& Insel, 2013), we aim to disentangle the different dimensions of shame proneness and to provide a clearer picture of its relation to psychopathology and social functioning.

\section{Maladaptive and Adaptive Conceptualizations of Shame Proneness}

A considerable amount of literature has conceptualized shame as being dysfunctional. Cognitive theories, such as the one by H. B. Lewis (1971), claim that shame arises when a person does not meet his or her own ideals which is typically followed by negative self-evaluations. Consequently, the ashamed person is increasingly self-focused with only little capacities for showing empathic concerns for others. In addition to this focus on internal processes in shame, some theorists consider shame to be a public experience because the transgression is visible to others (Kim, Thibodeau, \& Jorgensen, 2011). For example, Gilbert (1998) differentiates external from internal shame with external shame arising when a person anticipates creating a negative response in others.

Although previous work has primarily focused on maladaptive conceptualizations of shame, some researchers have conceptualized shame as serving an important adaptive function. For example, Barrett (1998) argues that shame helps individuals learn and respect social norms since people are motivated to avoid this highly aversive emotion. Conforming with social norms supports acceptance from others and may thus protect against social exclusion and may also ensure the maintenance of self-respect (see also Hilgers, 2006).

Due to the paradoxical relation between shame and maladaptive as well as adaptive correlates, we argue that different dimensions of shame contribute to these distinct associations (Scheel et al., 2013; Scheel et al., 2014). In the following, we focus on shame proneness and not on the momentary experience of the emotion of shame. A large amount of seminal work has focused on shame proneness (e.g., Mills et al., 2015; Muris, Meesters, Bouwman, \& Notermans, 2015; Tangney, Wagner, \& Gramzow, 1992) and has revealed adaptive and maladaptive correlates, such as inadequate anger reactions, interpersonal difficulties, withdrawal but also maintaining social norms and one's value system (e.g., Adamczyk, 2017; Gausel et al., 2016; Tangney et al., 1995; Tangney et al., 1996).

In this regard, we argue that adaptive dimensions of shame proneness support social functioning and mental health if it exists in moderate levels. Shame thus serves the adaptive function to follow social rules in order to avoid the aversive experience of shame which, in turn, may be related to maintaining one's social status. For example, a person wishes to sing a song while sitting in the library, however, anticipating the shameful feelings invoked by doing this inhibits the person from singing even if this goes against the person's impulse. Maladaptive dimensions of shame proneness, as opposed to adaptive dimensions, threaten social functioning and mental health because of its strong interconnection with negative self-evaluations and social inadequate behaviors. For example, a person with high maladaptive shame proneness who is complimented by another person may experience this as especially shameful and may, thus, react socially inadequately with hostility or by withdrawing.

\section{Previous Instruments for Measuring Shame}

Several instruments have been developed to assess shame. Most of the scales have been developed in clinical psychology and were constructed for patients suffering from mental illness (e.g., Andrews, Qian, \& Valentine, 2002; Averill, Diefenbach, Stanley, Breckenridge, \& Lusby, 2002; Cohen et al., 2011; Garcia, Acosta, Pirani, Edwards, \& Osman, 2017; Simonds et al., 2016). Yet, with regard to the functionality of shame, this prior research is limited because it has tended to overemphasize the maladaptive conceptualization of shame proneness but ignored adaptive dimensions of shame.

The latest version of the test of self-conscious affect- 3 (TOSCA-3; Tangney, Dearing, Wagner, \& Gramzow, 2000), for example, focuses on the maladaptive aspects of shame proneness. The TOSCA-3 is the most widely used instrument that has promoted numerous findings concerning the meaning of shame for social functioning and mental health (e.g., Guimón, Las Hayas, Guillén, Boyra, \& González-Pinto, 2007; Stuewig et al., 2015; Tangney et al., 1992). It assesses shame as well as guilt, externalization, and detachment by presenting hypothetical situations and hypothetical behavior responses. The assessment of shame is based on the conceptualization of shame as dysfunctional negative evaluations of the self (Tangney et al., 1995). Accordingly, behavioral responses related to shame in TOSCA-3 reflect exclusively maladaptive behavior such as dysfunctional social withdrawal or cognitions and negative self-evaluations.

Multidimensional instruments that have been developed to assess shame also follow a maladaptive conceptualization (e.g., Guilt and Shame Proneness Scale, Cohen et al., 2011; 
Multidimensional Shame-Related Response Inventory-21 [MSRI-21], Garcia et al., 2017; Adolescent Shame Proneness Scale, Simonds et al., 2016). For example, the MSRI-21 (Garcia et al., 2017) assesses affective and behavioral responses to shame. The three components include negative self-evaluation, fear of social consequences, and maladaptive behavior tendency. Similar to TOSCA-3, the MSRI-21 emphasizes dysfunctional behavior responses, whereas adaptive shame dimensions are underrepresented.

Taken together, there are several well established and validated instruments to assess shame proneness. Crucially, however, none of these scales focus on the multidimensional adaptive and maladaptive character of shame. Based on the present holistic approach to conceptualize shame proneness as a multifaceted transdiagnostic construct, we regard it as necessary that instruments consider both adaptive and maladaptive dimensions of shame.

\section{The Shame Assessment for Multifarious Expressions of Shame (SHAME)}

To analyze adaptive and maladaptive aspects of shame proneness, the SHAME (Scheel et al., 2013) was recently developed. The SHAME focuses on a multidimensional assessment of shame and provides two adaptive subscales (bodily and cognitive shame) and one maladaptive (existential shame) subscale. The dimensions were derived from Hilgers' (2006) concept of shame affect, as well as from interviews with patients suffering from mental health problems and with healthy participants. In his shame concept, Hilgers (2006) emphasized the self-regulatory function of shame to support achieving personal goals and adapting to the social environment.

Originally, Hilgers (2006) described the eight facets of (1) intimacy, (2) ideals, (3) competence, (4) autonomy or social exclusion, (5) oedipal shame, (6) existential shame, (7) dishonor, (8) and shame-guilt-dilemma. The last two facets were not included in the SHAME as they are either grounded in violent humiliation by others (dishonor) or conflicting demands leading either to shame or guilt (shame-guilt-dilemma).

The SHAME facet bodily shame comprises and extends features of the Facets 1 through 5 . Bodily shame reflects the tendency to experience shame concerning physical ideals, shape, face, intimacy, and sexuality. Bodily shame is conceptualized as arising when a person's physical ideals are violated, or parts of the body are exposed in uncontrolled or in inadequate situations.

Cognitive shame comprises features of the Facets 2 and 4 and it reflects the tendency to experience shame concerning cognitive and moral ideals, competence and social exclusion. Cognitive shame is evoked when a person violates his or her moral or social standards.
Existential shame (which is reflected in Facet 6) describes shame concerning the person itself, especially with respect to the experience of being worthless, irrelevant, and deficient. This maladaptive aspect of shame therefore is not limited to a specific set of situations. It can be distinguished from low self-esteem or mere negative self-evaluation by the intense experience of being ashamed. Whereas people high in existential shame are ashamed of themselves as a person, people high in bodily or cognitive shame do not experience their physical appearance or cognitive competences as shameful but, for example, the inappropriate disclosure of intimate zones of the body.

Therefore, the current conceptualization of the SHAME differs from previous theoretical conceptualizations of shame. In contrast to previous models which emphasized the maladaptive nature of shame (e.g., Dost \& Yagmurlu, 2008, H. B. Lewis, 1971; Tangney et al., 1995), the current model conceptualizes shame proneness as multifaceted with the adaptive dimension relevant to maintain social acceptance and functioning, and the maladaptive dimension related to perceiving oneself as a person as shameful and inferior.

Similar to the TOSCA, the SHAME is a scenario-based measure consisting of hypothetical situations that describe potentially shame relevant situations. However, in contrast to focusing on behavioral responses, the SHAME uses intensity ratings with respect to how much one would experience shame in a specific situation. Previous instruments, such as the TOSCA, often focus on behavioral tendencies that may come later in the emotion-generative process such as social withdrawal or aggressive reactions. In contrast, the current approach conceptualizes shame proneness as a tendency to emotional experiences that come earlier in the emotion-generative process (e.g., Ekman, 1972; Gross, 2001; Lazarus, 1991; Rosenberg, 1998; Scherer, 1984). In order to investigate adaptive and maladaptive dimensions of shame proneness, we argue that it is important to disentangle individual differences in shame-specific experiences in these dimensions from related adaptive or maladaptive outcomes or associated behavior. Thus, the SHAME focuses on the emotion itself as experienced by the individual in specific situations.

Based on the theoretical conceptualization as well as interviews with experts, patients, and healthy participants over 200 items were developed including prototypical shame situations. After a stepwise process of item reduction, the questionnaire confirmed good psychometric properties in a representative German sample (Scheel et al., 2013). Nonetheless, questions concerning its construct validity remain. In particular, concerning interpretation of the different-adaptive and maladaptive-aspects of shame, more information on their validity is needed. 


\section{Overview of the Present Research}

The goal of this work is to build on previous efforts by validating a new measure for empirically testing the conceptualization of shame proneness as composed of adaptive and maladaptive aspects. We argue that such an instrument would help provide a precise picture of the different correlates of shame and its influence on mental health outcomes.

In consideration of shame being described as an innate emotion that is present across different cultures (Tracy \& Matsumoto, 2008), we examined the dimensional factor structure of the SHAME using invariance testing in U.S. American and German community samples. Furthermore, we examined associations between the SHAME and relevant intrapersonal and interpersonal constructs using bifactor-model analyses, to place the adaptive and maladaptive dimensions of shame proneness within a nomological network of similar and dissimilar constructs. Additionally, we investigated the associations between psychopathology and adaptive and maladaptive shame dimensions by comparing these associations in a clinical sample and in community samples using network analyses.

To establish convergent validity, we expected the SHAME and each of its adaptive and maladaptive dimensions to show relevant associations to established instruments measuring shame.

As guilt and aggression have been shown to co-occur with shame in many situations (Blum, 2008; Velotti, Elison, \& Garofalo, 2014), both constructs needed to be separated from shame. We still expected there to be moderate interrelations with shame, as guilt and hostility - as a form of interpersonal aggression - are closely related to shame (e.g., Blum, 2008; Cherry, Taylor, Brown, Rigby, \& Sellwood, 2017; Scott et al., 2015; Velotti, Garofalo, Bottazzi, \& Caretti, 2017). With guilt being conceptualized as adaptive (Tangney et al., 2000), we expected positive interrelations with the adaptive dimensions and negative interrelatons with existential shame. As guilt, according to the definition by Tangney et al. (2000), is associated with perspective taking and social norms, the positive interrelation with cognitive shame should be prominent.

With regard to psychopathology, we expected moderate correlations on the basis that many studies have reported associations between shame proneness and psychopathology (Adamczyk, 2017; Andrews, Brewin, Rose, \& Kirk, 2000; Brown et al., 2009; Castilho, Pinto-Gouveia, \& Duarte, 2017; Duarte, Pinto-Gouveia, \& Stubbs, 2017). Considering that the dimension existential shame is conceptualized as the maladaptive aspect of shame proneness, it should have the strongest associations with psychopathology.

To establish discriminant validity, we included the construct of self-control. Although shame often occurs in situations of loss of control (Catarino \& Gilbert, 2016;
Patock-Peckham, Canning, \& Leeman, 2018), shame proneness has to be differentiated from low self-control skills.

We also compared the associations between the SHAME and several symptomatic patterns of mental health in patients suffering from Borderline Personality Disorder (BPD) and in participants from community samples to improve understanding of the adaptive and maladaptive aspects of shame proneness. We chose a sample of patients suffering from BPD, on the basis that BPD and BPD-related symptoms such as self-injury (Brown et al., 2009; Schoenleber, Berenbaum, \& Motl, 2014), anger problems (Peters, Geiger, Smart, \& Baer, 2014; Velotti et al., 2014), suicidality (Harned, Korslund, \& Linehan, 2014), and relationship problems (Black et al., 2013) have been shown to be associated with shame.

\section{Method}

\section{Participants}

For the present investigation, we used data from three different samples. We collected data from 502 participants (Sample 1) using Amazon's Mechanical Turk (MTurk). Country of origin was restricted to the United States and only "advanced workers" were included to improve data quality. Data collected using MTurk have shown high-quality and diversity (Buhrmester, Kwang, \& Gosling, 2011). In this sample, $41.2 \%$ of the participants were male $(n=207)$ and $58.4 \%$ were female $(n=293)$; two participants did not specify their sex. According to education level, 9.6\% $(n=$ $48)$ indicated to have a postgraduate degree, $35.1 \%(n=$ 176) a bachelor degree, $14.1 \%(n=71)$ an associate degree, $27.9 \%(n=140)$ some college but no degree, $10.8 \%(n=$ $54)$ a high school degree or equivalent, and $2.2 \%(n=11)$ less than high school degree. The mean age of participants was 36.6 years $(S D=11.6)$. Participants confirmed their informed consent online before starting to fill in the questionnaire package. The study was approved by the institutional ethics board of the University of Colorado. All participants received $\$ 2$ for participation.

In addition to the U.S. American sample, a representative German sample (Sample 2) was included to test for factorial invariance between both samples. Data from Sample 2 were collected as part of a larger project (Scheel et al., 2013; Scheel et al., 2014), but invariance testing procedures were not previously conducted in this project. Two thousand participants from the registration office of Freiburg, Germany, were initially addressed. With a rate of $25 \%, 496$ participants with an average age of 45.1 years $(S D=16.6)$ and $40.3 \%$ male participants $(57.1 \%$ female; $2.6 \%$ did not specify their sex) responded to the invitation. The final sample did not differ regarding age and gender as verified by $\chi^{2}$ test from the originally addressed representative sample of 
2,000 people (see Scheel et al., 2013, for a detailed description of the sample).

As we aimed to investigate the relations between adaptive and maladaptive aspects of shame and psychopathology, we also included a clinical sample (Sample 3). Assessments took place as part of a larger project (Scheel et al., 2014), but associations between shame and selfreported psychopathological symptoms were not previously investigated in this project. In the present research, we included 92 female patients suffering from BPD with an average age of 28.0 years $(S D=7.5)$. All patients underwent structured clinical interviews for Axis I and II disorders (SCID I; Spitzer, Williams, Gibbon, \& First, 1992; German version: Wittchen, Wunderlich, Gruschwitz, \& Zaudig, 1997; SCID II; First, Spitzer, Williams, \& Gibbon, 1997; German version: Fydrich, Renneberg, Schmitz, \& Wittchen, 1997).

\section{Measures}

Shame proneness was assessed in Samples 1, 2, and 3 using the SHAME (Scheel et al., 2013). The SHAME consists of three subscales, two representing adaptive shame aspects (bodily shame: e.g., "I try on an article of clothing that I can barely get into. During this my boyfriend or girlfriend looks in the changing room." and cognitive shame: e.g., "I am praised for something that I did not accomplish myself."), and one representing maladaptive (existential) shame (e.g., "I ask myself, what would someone else who would have been born instead of me, in the same situation, have done with their life."). The questionnaire consists of 21 items in total, with 7 items per subscale. Each item describes a short scenario. Participants are asked to rate how intensely they would feel shame in the presented situation on a 6-point Likert-type scale. The response scale ranges from not at all (0) to an extreme amount (5). The SHAME was constructed in German (Scheel et al., 2013). For purposes of cross-validation with an English-speaking sample, the SHAME was translated into English by a bilingual native speaker. This version was translated back into German by a second bilingual person. The original German version and the backtranslation were compared for item content by a third person. The item formulations, descriptive statistics, and coefficients of internal consistency for all three samples are displayed in Table 1. The German version of the SHAME may be requested from the first author (see also Scheel et al., 2013).

Self-conscious emotions were measured with the TOSCA-3 (Tangney et al., 2000). We included its latest revised short version TOSCA-3 (Tangney et al., 2000) in Sample 1. The short version comprises 10 scenarios with each item describing a situation and four behavioral response options. Participants are asked to rate the probability of each reaction on a 5-point Likert-type scale ranging from 1 (not likely) to 5 (very likely). The behavior responses refer to responses associated with shame, guilt, detachment, and externalization. Within the U.S. American sample, the TOSCA-3 showed reasonable internal consistency as measured with Cronbach's alpha (shame: $\alpha=.82$, detached: $\alpha=.79$, guilt: $\alpha=.75$, and externalization: $\alpha=.81$ ).

Aggression was assessed in Sample 1 using the Aggression Questionnaire (AQ; Buss \& Perry, 1992). With this questionnaire, four aspects of aggression, verbal and physical aggression, anger and hostility, are assessed by means of 29 items. All items are presented in a 5-point Likert-type format ranging from 1 (extremely uncharacteristic for me) to 5 (extremely characteristic for me). The AQ provided good internal consistency with $\alpha=.94$ for the AQ-total score, $\alpha=.88$ for the AQ-physical aggression score, $\alpha=.78$ for the AQ-verbal aggression score, $\alpha=.82$ for the AQ-anger score, and $\alpha=.89$ for the AQ-hostility score in the U.S. American sample.

Psychopathology was assessed in Samples 1, 2, and 3 with the Brief Symptom Inventory (BSI; Derogatis, 2000), which includes the subscales somatization, depression, and anxiety. The general severity index (GSI), which reflects the BSI total score, represents the psychopathological burden the participant experienced within the past week. Items are answered on a 5-point Likert-type scale ranging from 0 (not at all) to 4 (extremely). BSI showed satisfying internal consistency with GSI: $\alpha=.94$, for the U.S. American sample; GSI: $\alpha=.95$, for the German sample, and GSI: $\alpha=.92$ for the clinical sample.

Self-control was measured in Sample 1 with the SelfControl Scale (Tangney, Baumeister, \& Boone, 2004). The Self-Control Scale consists of 13 items including a 5-pointLikert-type scale that ranges from 1 (not at all) to 5 (very $m u c h)$. The internal consistency was good $(\alpha=.90)$ within the U.S. American sample.

\section{Analyses}

Invariance Testing. To cross-validate the factorial structure of the SHAME in the English-speaking context, we ran confirmatory factor analyses with the Mplus version 7 statistics program (Muthén \& Muthén, 2012), using maximum likelihood estimation with robust standard errors. To test for factorial invariance across the U.S. American sample and the German sample, a hierarchically arranged set of analytical steps was carried out. First, we determined a configural model that corresponded with the proposed model of the SHAME (Scheel et al., 2013) for both samples (Model A). The model contains three correlated factors that reflect bodily, cognitive, and existential shame. Furthermore, for exploratory purposes, we included correlated residuals between Items 1 to 8,1 to 15 , and 8 to 15 (all bodily shame) and between Items 4 to 5,5 to 10 , and 4 to 10 (all cognitive shame; see Table 1 for item formulations) to account for 


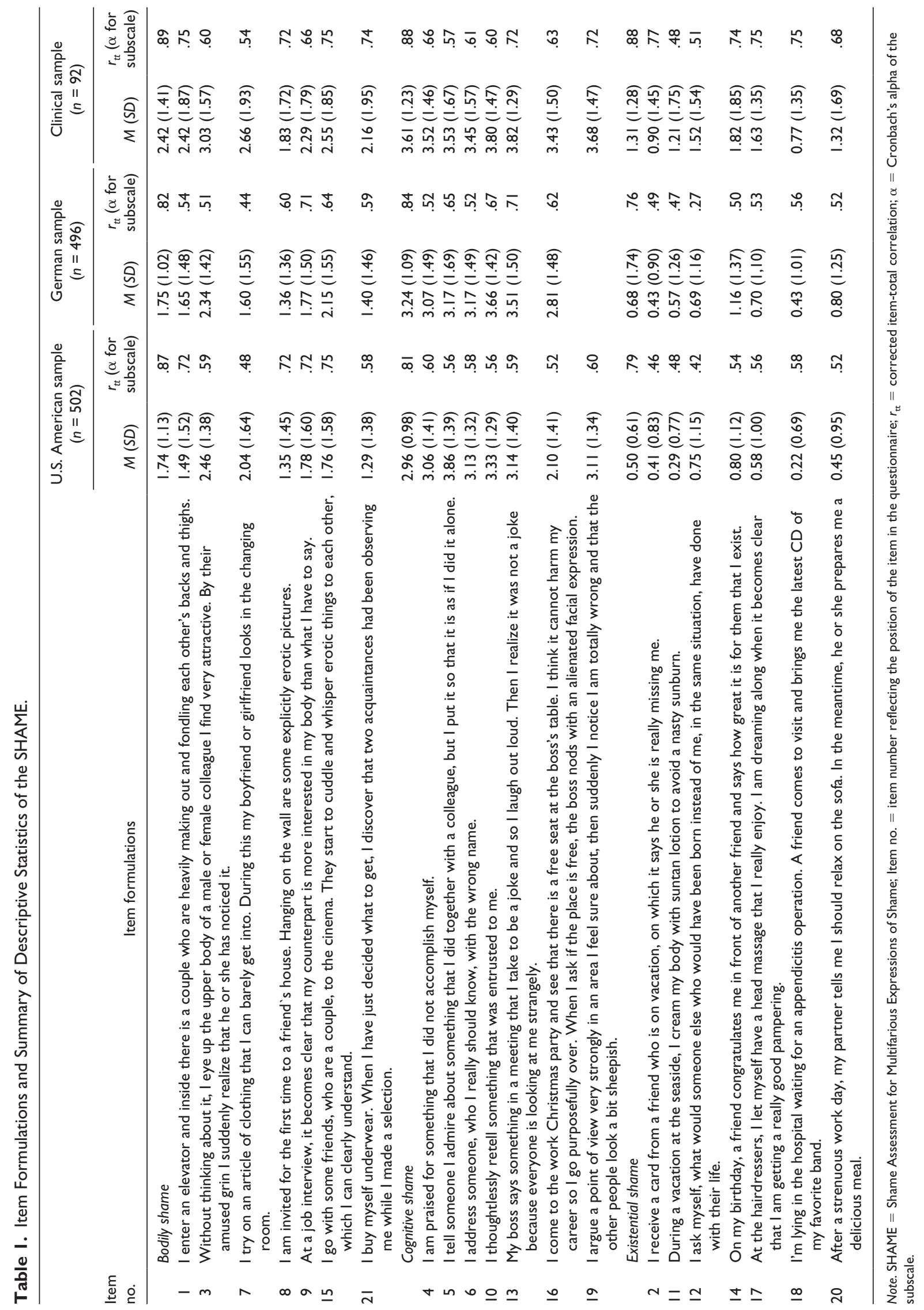


similar item content referring to erotic content and moral standards (see also Scheel et al., 2013). Then, a series of increasingly restrictive models were compared against each other to examine invariance (Meredith, 1993). Parameters were considered invariant when there was no substantive drop in model fit $(\Delta$ CFI [comparative fit index] $<.01)$ between two steps (Cheung \& Rensvold, 2002). Invariance in the factor loadings would imply that the unit of measurement for latent factors was equal across the samples (Model B). In addition, we imposed equality constraints on the residual covariances (Model C) and tested for scalar invariance by imposing equality constraints on the item intercepts (Model D) as well as structural invariance by imposing equality constraints on the factor variances and covariances (Model E). We additionally established measurement invariance across gender, with the results displayed in the supplementary material (see Table S1 [All supplementary materials are available in the online version of the article.]).

Bifactor Model Analyses. An aim of the current study was to investigate the nomological network of shame proneness including its adaptive and maladaptive facets. To investigate convergent and discriminant validity, we examined associations between the total score and the subscales of the SHAME and the measures of self-conscious emotions, aggression, psychopathology, and self-control. To differentiate shame from guilt, we used partial relations controlling for guilt (resulting in "guilt-free-shame"), or controlling for shame (resulting in "shame-free-guilt"), following suggestions by Tangney et al. (2000). We analyzed bifactor models to investigate the unique association between the SHAME and the other measures (F. F. Chen, Hayes, Carver, Laurenceau, \& Zhang, 2012; F. F. Chen, West, \& Sousa, 2006). Bifactor models included a general factor that accounts for the commonality shared by all specific factors of shame proneness (i.e., bodily, cognitive, and existential shame), and the specific factors that reflect the single dimensions of shame proneness. In a bifactor model, the general and the specific factors are used to simultaneously predict external variables (F. F. Chen et al., 2006). An important advantage of the bifactor model (in contrast to, for example, bivariate correlations), is that it allows to simultaneous testing and comparison of the unique relations for each of the specific factors and the general factor (Chen et al., 2012). Bifactor models were calculated using Mplus version 7 (Muthén \& Muthén, 2012).

Network Analyses. In the present research, network analyses were used to investigate the distinctive associations between the different dimensions of shame and psychopathology. The novel approach of network analysis facilitates visualization, description, and significance testing of relations between variables while controlling for the influence of other variables. In network analysis, variables are called nodes and relations between variables are called edges. In the present analyses, we entered bodily, cognitive, and existential shame, as well as different forms of psychopathology, as the observed nodes of the network. Edges may be described as partial correlations controlling for all other relationships in the network. Network analyses were conducted using the R packages qgraph (Epskamp, Cramer, Waldorp, Schmittmann, \& Borsboom, 2012) and bootnet (Epskamp, Borsboom, \& Fried, 2017). Analyses follow suggestions from Epskamp et al. (2017). To meet potential difficulties of interpretation, we followed the conservative way of regularization and interpretation.

First, network models were estimated for each of the three samples. Additional network models were estimated separately for women and men of the U.S. American and the German sample, to allow a comparison with thefemale only - clinical sample (results for male subsamples may be found in the supplementary material). For the estimation of these network models an adjusted Gaussian graphical model (Lauritzen, 1996) was used. The analyses conducted with the qgraph package provide conservative networks because the algorithm suppresses instable, random, and irrelevant edge-weights. It utilizes graphical least absolute shrinkage and selection operator (glasso; Tibshirani, 1996) combined with extended Bayesian information criterion model selection (J. Chen \& Chen, 2008) to estimate a regularized and parsimonious Gaussian graphical model. Based on regularization, only a small number of edge-weights (partial correlation coefficients, $r_{p}$ ) are used to explain covariation, while edge-weights close to zero are dropped from the model. Furthermore, the following centrality indices that provide information about the impact of a node in its network were estimated: strength describes the absolute sum of edge-weights connected to a node, closeness stands for the average distance from the observed node to all other nodes in the network, and betweenness for the number of times in which the node lies on the shortest paths between two other nodes. All estimated network models and centrality indices were checked with respect to accuracy and stability before interpreting the results: Nonparametric bootstrapped $95 \%$ confidence intervals (CIs) were calculated as accuracy parameters for all edges of each estimated network separately (Epskamp et al., 2017). The correlation stability coefficient (CS; $r=.70$ ) was calculated as an indicator of stability (Epskamp et al., 2017). Additionally, significant differences between the edge-weight parameters were tested within each network.

With respect to network analyses in Sample 1 (U.S. American sample) and in Sample 2 (German sample), we investigated the associations between the dimensions of the SHAME and the psychopathological symptom patterns of depression, anxiety, and somatization. Due to smaller sample sizes in Sample 3 (clinical sample $n=92$ ) and in the 
Table 2. Model Fit Indices From the Invariance Testing Procedures for United States and Germany.

\begin{tabular}{|c|c|c|c|c|c|c|}
\hline Model & $x^{2}$ & $d f$ & $\mathrm{CFI}$ & RMSEA $[90 \% \mathrm{Cl}]$ & Model comparison & $\Delta \mathrm{CFI}$ \\
\hline Model A (configural model) & 896.166 & 360 & .916 & $.055[.050, .059]$ & & - \\
\hline Model B (equal factor loadings) & 960.320 & 378 & .908 & $.056[.05 \mathrm{I}, .060]$ & A vs. $B$ & .008 \\
\hline $\begin{array}{l}\text { Model } \mathrm{C} \text { (equal factor loadings and equal residual } \\
\text { covariances) }\end{array}$ & 988.049 & 384 & .905 & $.056[.052, .060]$ & B vs. $C$ & .003 \\
\hline $\begin{array}{l}\text { Model D (equal factor loadings, residual covariances, and } \\
\text { partially equal item intercepts) }\end{array}$ & 1050.480 & 399 & .897 & $.057[.053, .06 \mathrm{I}]$ & C vs. D & .009 \\
\hline $\begin{array}{l}\text { Model E (equal factor loadings, equal residual } \\
\text { covariances, partially equal item intercepts, }{ }^{\text {a }} \text { equal } \\
\text { factor covariances, and variances) }\end{array}$ & 1077.84 & 405 & .894 & $.058[.054, .062]$ & D vs. E & .003 \\
\hline
\end{tabular}

Note. $\mathrm{CFI}=$ comparative fit index; RMSEA = root mean square error of approximation; $d f=$ degrees of freedom; $\mathrm{Cl}=\mathrm{confidence}$ interval; $\Delta \mathrm{CFI}=$ drop in model fit from comparing the comparative fit index for the corresponding model with the preceding model; U.S. American sample ( $n$ ) = 502; German sample $(n)=496$.

${ }^{a}$ Three item intercepts were freed.

female subsamples of Sample $1(n=293)$ and $2(n=289)$, we had to reduce the number of nodes in order to calculate interpretable models (Epskamp et al., 2017). Accordingly, the GSI was entered as an index of psychopathology only in the network models in Sample 3 and in the female subsamples of Samples 1 and 2.

Scripts for all analyses can be found in the open-science framework (Scheel \& Rentzsch, 2018).

\section{Results}

\section{Invariance Testing}

Using invariance testing procedures, the configural model of the SHAME revealed satisfying model fit $(\mathrm{CFI}=.916$, root mean square of approximation [RMSEA] $=.055$ ) across the English-speaking and the German-speaking context. Analyses indicated factorial invariance of the SHAME; factor loadings were invariant across languages as displayed in Table 2. ${ }^{1}$ Testing for scalar and structural invariance indicated partial scalar invariance and structural invariance including three freed items.

Results provided support for the applicability of the SHAME in the English-speaking context and for the factorial structure of shame proneness comprising the three distinct but correlated dimensions of bodily, cognitive, and existential shame.

\section{Bifactor Model Analyses}

To test for convergent and discriminant validity of the SHAME, we first established a bifactor model of the SHAME and investigated ancillary indices of the bifactor model. The bifactor model reached satisfying model fit, CFI $=.94$ and RMSEA [90\% CI $]=.049[.042, .056]$. Regarding model-based reliability (Rodriguez, Reise, \& Haviland, 2016), the total score exhibited reliability of $\omega=.92$, and the subscale scores of bodily, cognitive, and existential shame $\omega=.89, .83$, and .78 , respectively. Indeed, $84.3 \%$ of the reliable variance in the total score was due to the general factor, and $21.7 \%, 31.2 \%$, and $73.8 \%$ of the reliable variance in each subscale score was due to its specific factor of bodily, cognitive, and existential shame, respectively. Furthermore, explained common variance (Rodriguez et al., 2016) by the general factor was $.63(p<.001)$, indicating that besides the general factor, also the specific factors may have value. The proportion of common variance that is explained by one specific factor was $.16(p=.48), .12(p<.001)$, and $.09(p=.02)$ for bodily, cognitive, and existential shame, respectively. The percentage of uncontaminated correlations of .70 indicated that the current model is not essentially unidimensional, but also contains multidimensional aspects (Reise, Scheines, Widaman, \& Haviland, 2013). Furthermore, comparing the loadings between the specific factors and the general factor revealed a mixed pattern with some items loading stronger on the specific factor and others loading stronger on the general factor. Investigating the individual explained common variance of every item (Stucky, Thissen, \& Edelen, 2013) showed that 10 items reflected its specific factor more than the general factor (i.e., IECV $\leq .50$ ), 6 items reflected the general factor more than the specific factor (i.e., IECV $>.50$ ), and 5 items were strong measures of the general dimension (IECV $>.85)$. In total, ancillary measures indicated that the SHAME can be conceptualized as a multidimensional instrument, despite the presence of a general factor.

Bifactor-models analyzing the unique association between the SHAME and other measures were then calculated to test for convergent and discriminant validity of the SHAME with results displayed in Table 3. All bifactor models reached satisfying model fit between $\chi^{2}(179)=430.469, \mathrm{CFI}=.94$ and RMSEA [90\% CI] $=.052[.057, .059]$ and $\chi^{2}(179)=$ 499.791, CFI $=.93$, and RMSEA $[90 \% \mathrm{CI}]=.060$ 
Table 3. Summary of Descriptive Statistics and Relations of the SHAME to External Variables.

\begin{tabular}{|c|c|c|c|c|c|c|c|c|c|c|}
\hline & \multirow[b]{3}{*}{$M(S D)$} & \multicolumn{8}{|c|}{ SHAME } & \multirow{3}{*}{$\begin{array}{c}\text { TOSCA } \\
\text { Shame } \\
r_{a}\end{array}$} \\
\hline & & \multicolumn{2}{|c|}{ Total } & \multicolumn{2}{|c|}{ Bodily shame } & \multicolumn{2}{|c|}{ Cognitive shame } & \multicolumn{2}{|c|}{ Existential shame } & \\
\hline & & $\beta$ & $r$ & $\beta$ & $r$ & $\beta$ & $r$ & $\beta$ & $r$ & \\
\hline TOSCA “guilt-free shame” & $3.14(0.54)$ & $.51 * *$ & $.48^{* *}$ & $-.09 *$ & $.43^{* *}$ & $.17 *$ & $.39 * *$ & $.10 *$ & $.32 * *$ & \\
\hline TOSCA “shame-free guilt” & $3.98(0.77)^{\mathrm{a}}$ & -.05 & -.02 & .04 & -.08 & $.20 *$ & $.26 * *$ & $-.29 * *$ & $-.28 * *$ & \\
\hline Aggression (AQ), Total score & $2.24(0.73)$ & $.15 * *$ & $.13 * *$ & $-.1 I *$ & $.11 *$ & -.04 & .04 & $.35 * *$ & $.34 * *$ & $.34 * *$ \\
\hline Verbal aggression & $2.48(0.85)$ & -.05 & -.02 & -.08 & $-.12 * *$ & .08 & -.08 & $.26 * *$ & $.15^{* *}$ & $.12 * *$ \\
\hline Physical aggression & $2.06(0.83)$ & .00 & .02 & -.11 & -.01 & -.06 & $-.12 * *$ & $.33 * *$ & $.26 * *$ & .08 \\
\hline Anger & $2.01(0.82)$ & $.20 * *$ & $.16 * *$ & -.11 & $.15^{* *}$ & $-.13 *$ & -.03 & $.29 * *$ & $.34 * *$ & $.32 * *$ \\
\hline Hostility & $2.4 I(0.96)$ & $.28 * *$ & $.23 *$ & $-.18 *$ & $.20 * *$ & .01 & .08 & $.25 * *$ & $.32 * *$ & $51 * *$ \\
\hline Psychopathology (BSI), BSI-GSI & I.63 (0.76) & $.28 * *$ & $.32 * *$ & -.06 & $.26 * *$ & .04 & $.14 * *$ & $.4 I * *$ & $.45^{* *}$ & $.39 * *$ \\
\hline BSI-somatization & $\mathrm{I} .45(0.62)$ & $.24 * *$ & $.32 * *$ & .09 & $.29 * *$ & .01 & $.11 *$ & $.43 * *$ & $.45^{* *}$ & $.28^{* *}$ \\
\hline BSI-depression & I.8I (0.97) & $.25 * *$ & $.26 * *$ & $-.14 *$ & $.19 * *$ & $.06 * *$ & $.14 * *$ & $.31 * *$ & $.35^{* *}$ & $.4 I^{* *}$ \\
\hline BSI-anxiety & I.63 (0.46) & $.26 * *$ & $.31 * *$ & -.02 & $.26 * *$ & .04 & $.13 * *$ & $.40 * *$ & $.43 * *$ & $.35^{* *}$ \\
\hline Self-control (SCS) & $3.40(0.80)$ & $-.18 * *$ & $-.10^{*}$ & $.16 *$ & $-.12 * *$ & $.16 *$ & .05 & $-.17 *$ & $-.24 * *$ & $-.29 * *$ \\
\hline
\end{tabular}

Note. $\beta=$ standardized regression coefficient from bifactor models with significant coefficients in boldface; $r=$ Pearson correlation coefficient; $r_{\mathrm{a}}=$ partial correlation coefficient (TOSCA-shame controlled for TOSCA-guilt); TOSCA = test of self-conscious affect; $A Q=$ Aggression Questionnaire; SCS = Self-Control Scale; BSI = Brief Symptom Inventory; GSI = general severity index; $n=502$ (U.S. American sample).

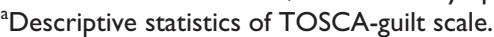

$*_{p}<.05 . * * p<.001$.

$[.054, .063]$. The general factor of shame proneness showed the strongest positive relation with TOSCA "guilt-free shame" $(\beta=.51, p<.001)$ as well as moderate positive associations with hostile aggression $(\beta=.28, p<.001)$ and psychopathology $(\beta=.28, p<.001)$, highlighting convergent validity. A small negative relation was observed for selfcontrol $(\beta=-.18, p<.001)$. Results of bifactor-models showed no relevant relation between the SHAME and TOSCA's "shame-free guilt" $(\beta=-.05, p=.40)$. Based on the zero to small relations between shame and self-control as well as "shame-free-guilt," results supported the discriminant validity of the SHAME.

Analyses also provided support for the construct validity of adaptive and maladaptive aspects of shame proneness. Whereas the maladaptive dimension of existential shame revealed unique positive relations to aggression $(\beta=.35$, $p<.001)$ and psychopathology $(\beta=.41, p<.001)$, this was not the case for the adaptive dimensions of bodily and cognitive shame. There were no significant positive associations between the adaptive aspects of shame and aggression (bodily shame: $\beta=-.11, p=.03$; cognitive shame: $\beta$ $=-.04, p=.57$ ) or psychopathology (bodily shame: $\beta=$ $-.06, p=.29$; cognitive shame: $\beta=.04, p=.50)$. The significant negative relationship between bodily shame and aggression was primarily due to the significant negative association between bodily shame and hostility $(\beta=-.18$, $p=.01)$. Table 3 provides an overview of bifactor model analyses results and additionally includes results from correlation analyses.

\section{Network Analyses}

Network analyses were used to examine differences in the associations between shame proneness dimensions and psychopathology across samples with and without mental health problems. In the following, we present results from network analyses for Samples 1 and 2 (U.S. American and German community samples) followed by results for the female subsamples and the (female) clinical sample (Sample 3). All networks showed satisfying accuracy and stability, which is important for interpretation. Table 4 provides stability parameters, $C S(r=.7)$, for the centrality indices of strength, closeness, and betweenness. Results revealed satisfactory to good stability of all estimated network models with respect to their strength. In accordance with previous research on sample sizes smaller than 1,000 (Epskamp et al., 2017), the stability of closeness and betweenness, however, was not sufficient across samples. ${ }^{2}$ (See also supplementary material for an overview of estimated centrality indices.)

Figure 1 visualizes the network models for the U.S. American and German community samples and Figure 2 displays estimated networks for both female subsamples and the clinical sample. ${ }^{3}$ In the U.S. American sample, existential shame exhibited unique connections with the psychopathological symptomatic patterns of anxiety $\left(r_{p}=.13\right)$ and somatization $\left(r_{p}=.17\right)$. Somatization was also related, but to a smaller extent, to bodily shame $\left(r_{p}=.07\right)$ and negatively to cognitive shame $\left(r_{p}=-.03\right)$. Depression was related to cognitive shame to a small extent $\left(r_{p}=.02\right)$. In 
Table 4. Stability Parameter CS( $r=.7)$ for Centrality Indices of Network Models.

\begin{tabular}{|c|c|c|c|c|}
\hline & \multirow[b]{2}{*}{$n$} & \multicolumn{3}{|c|}{$\mathrm{CS}(r=.7)[95 \% \mathrm{Cl}]$} \\
\hline & & Strength & Closeness & Betweenness \\
\hline \multicolumn{5}{|l|}{ Network models with six nodes ${ }^{a}$} \\
\hline U.S. American sample & 502 & $.749[.671,1]$ & $.205[.127, .283]$ & $0[0, .050]$ \\
\hline German sample & 496 & $.36 /[.284, .440]$ & $.206[.127, .284]$ & $.206[.127, .284]$ \\
\hline \multicolumn{5}{|l|}{ Network models with four nodes ${ }^{b}$} \\
\hline U.S. American female sample & 293 & $.751[.672,1]$ & $.75 \mathrm{I}[.672, \mathrm{I}]$ & $.672[.594, .75 I]$ \\
\hline German female sample & 289 & $.595[.516, .671]$ & $.516[.439, .595]$ & $.204[.128, .284]$ \\
\hline Clinical sample & 92 & $.522[.435, .598]$ & $.435[.359, .522]$ & $0[0, .054]$ \\
\hline
\end{tabular}

Note. $\mathrm{CS}=$ correlation stability coefficient; $\mathrm{Cl}=$ confidence interval; BSI = Brief Symptom Inventory; SHAME= Shame Assessment for Multifarious Expressions of Shame. Values above the preferable score of .5 are in bold face, acceptable values, above .25 in italics.

${ }^{a}$ Networks include three nodes for SHAME (bodily, cognitive, and existential shame) and three nodes for psychopathology (BSI-depression, BSI-anxiety, and BSI-somatization). ' $\mathrm{Networks} \mathrm{include} \mathrm{three} \mathrm{nodes} \mathrm{for} \mathrm{SHAME} \mathrm{(bodily,} \mathrm{cognitive,} \mathrm{and} \mathrm{existential} \mathrm{shame)} \mathrm{and} \mathrm{one} \mathrm{node} \mathrm{for} \mathrm{psychopathology} \mathrm{(BSI-}$ general severity index). CS $(r=.70)$ maximum drop proportions to retain correlation of .70 in at least $95 \%$ of the samples.

the German community sample, existential shame was also related to somatization $\left(r_{p}=.06\right)$, and, additionally, to depression $\left(r_{p}=.06\right)$. In contrast to the U.S. American sample, the German sample revealed further associations between bodily shame and depression $\left(r_{p}=.04\right)$ and between bodily shame and anxiety $\left(r_{p}=.13\right)$. Difference tests between the edge-weights for the U.S. American sample revealed significant differences comparing the relations between existential shame and somatization with the relations between cognitive shame and somatization (see Figure 3 for more details). Results indicate the positive association of existential shame and psychopathology to be stronger than the association of cognitive shame and psychopathology. No significant differences were detected for the German community sample.

In the following, associations between shame proneness and psychopathology in the two female subsamples and the clinical sample are presented (see Figure 2 for more detail). All three samples revealed unique associations between the dimension of existential shame and psychopathology (U.S. American women: $r_{p}=.35$, German women: $r_{p}=.17$, clinical sample: $\left.r_{p}=.56\right)$. The connection between existential shame and psychopathology was particularly pronounced in the clinical sample. In addition, the German subsample and the clinical sample exhibited relations between the dimension of bodily shame and psychopathology (German women: $r_{p}=.29$, clinical sample: $r_{p}=.22$ ). Difference tests between the edge-weights in the clinical sample revealed that the existential shame - psychopathology connection was significantly stronger than the bodily shamepsychopathology connection. Difference tests are displayed in Figure 4.

Results of network analyses provided support for the close relationship between existential shame and psychopathological symptomatic patterns, especially in female participants suffering from mental health problems.

\section{Discussion}

A large body of research revealed that shame is associated with adaptive and maladaptive correlates. However, previous measures of shame have focused mostly on the maladaptive aspects. The goal of this work was to validate a new dimensional assessment measure (SHAME), which was designed to disentangle adaptive and maladaptive dimensions of shame proneness. Psychometric properties indicate that the SHAME is a reliable and valid instrument for measuring shame proneness in the English and German language contexts. Results from confirmatory factor analyses, bifactor analyses and network analyses, based on three different samples, supported a valid differentiation into adaptive (bodily and cognitive shame) and maladaptive (existential shame) dimensions of shame proneness. Distinct relations of the different dimensions with similar and dissimilar constructs highlight the role of shame proneness for psychopathology and social functioning.

Our findings support the conceptualization of shame proneness as a multidimensional construct. Factor analyses in two different samples provide evidence for the multidimensional structure of shame proneness. In accordance with previous research revealing adaptive and maladaptive correlates of shame (e.g., Iannaccone et al., 2016; Murphy \& Kiffin-Petersen, 2017; Nazarov et al., 2015; Scott et al., 2015), our analyses established three dimensions of shame proneness: bodily, cognitive, and existential shame. In addition, ancillary measures from bifactor model analyses showed that the SHAME can be conceptualized as a multidimensional instrument, despite the presence of a general factor. The differentiation was further supported by unique relations between the dimensions of shame proneness and other similar and dissimilar constructs. As expected, the SHAME provides convergent validity by showing the strongest association with an established instrument for 

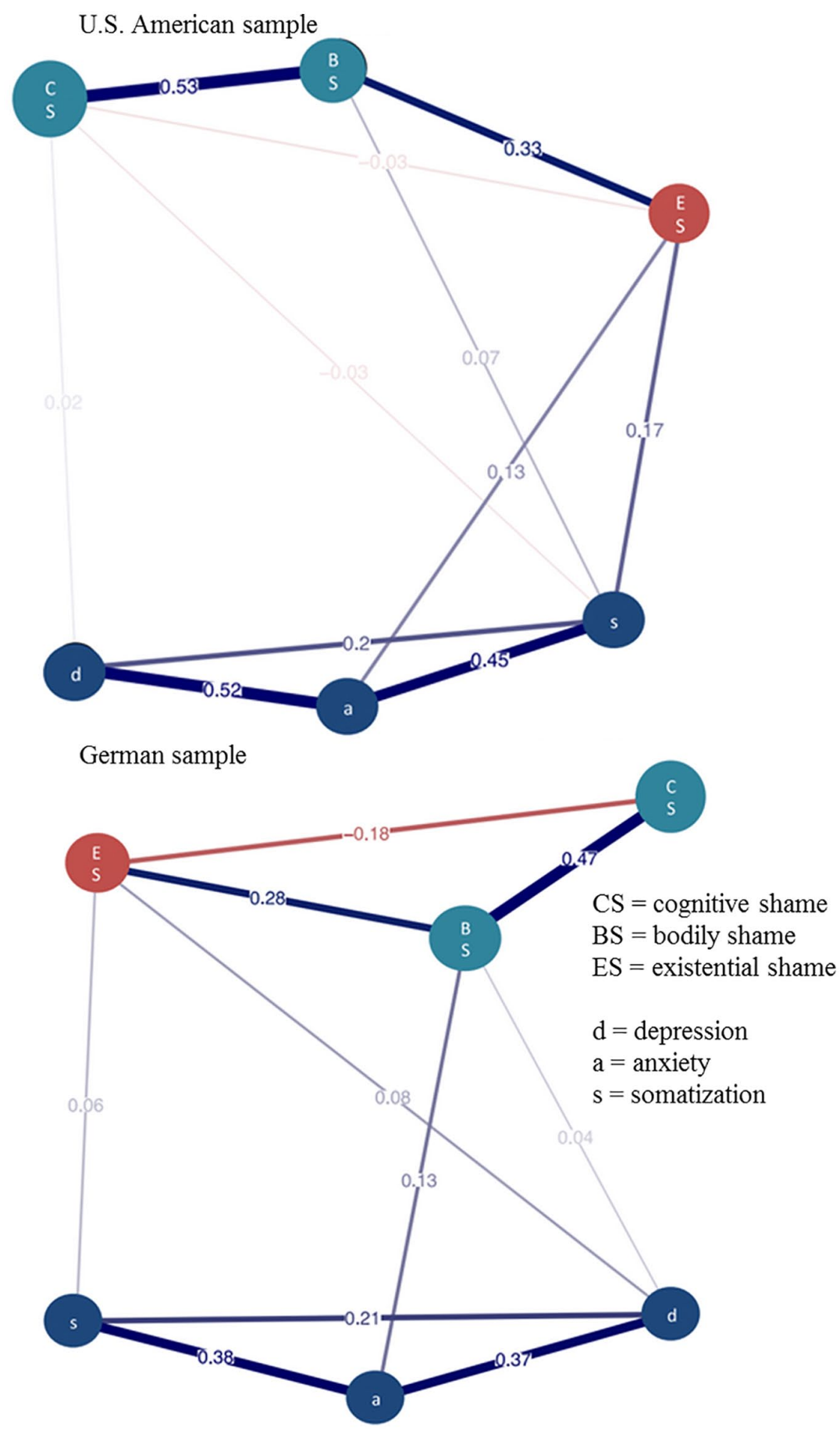

Figure I. Estimated networks of shame proneness facets and psychopathology in community samples.

Note. U.S. American sample $(n)=502$; German sample $(n)=496$. Upper nodes represent subscales of the Shame Assessment for Multifarious Expressions of Shame, lower nodes represent subscales of the Brief Symptom Inventory. Network structures are Gaussian graphical models, that is, networks of partial correlation coefficients.

measuring shame, the TOSCA-3 (Tangney et al., 2000), with particularly strong associations for each dimension of the SHAME with the TOSCA-3 "guilt-free shame."
Furthermore, we found a negative relation for the maladaptive aspect of shame (existential shame) with "shame-free guilt." These findings highlight the maladaptive character 


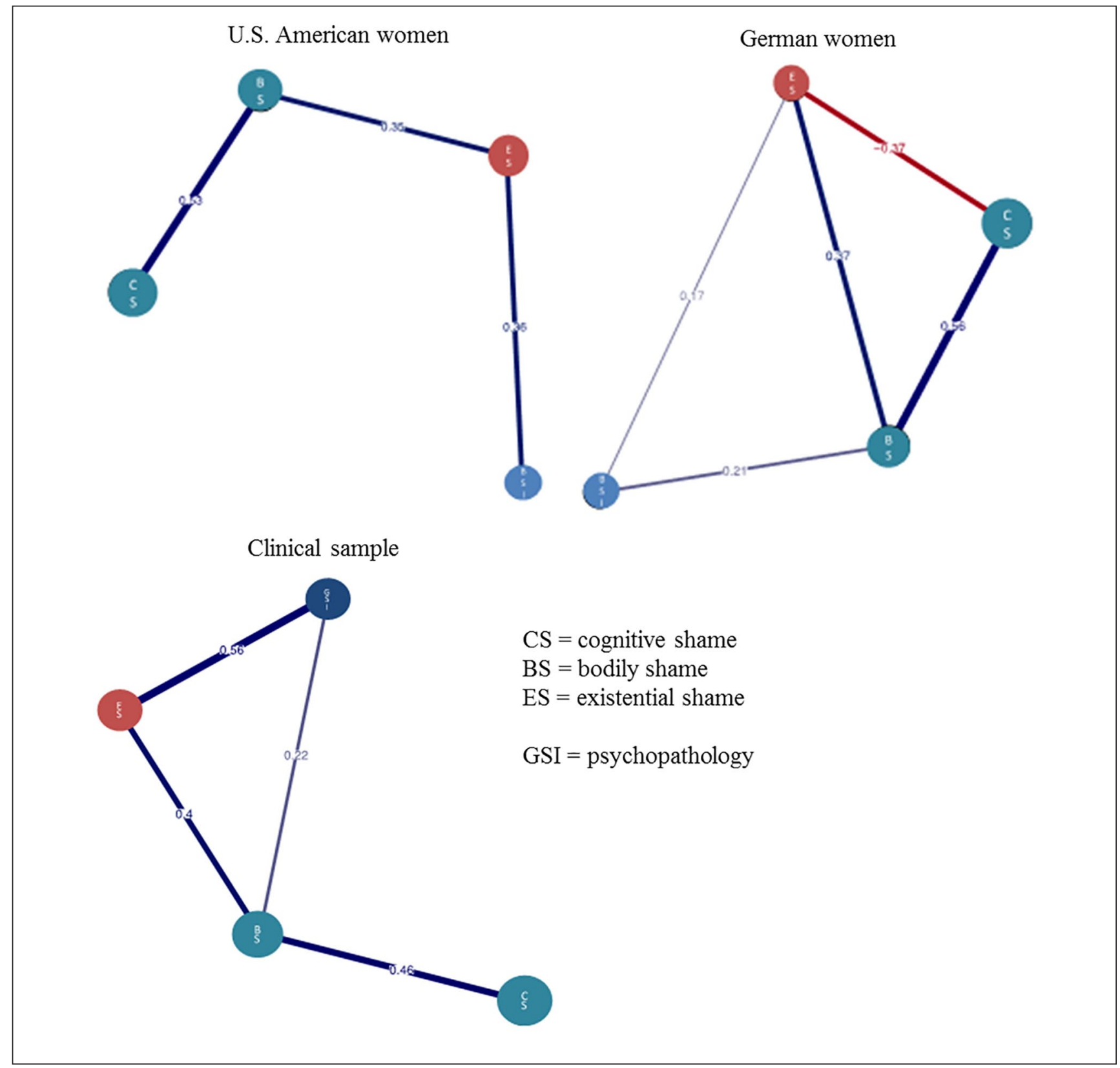

Figure 2. Estimated networks of shame proneness facets and psychopathology in female subsamples.

Note. U.S. American women $(n)=293$; German women $(n)=289$; clinical sample $(n)=92$. Nodes represent subscales of the Shame Assessment for Multifarious Expressions of Shame and general severity index of the Brief Symptom Inventory. Network structures are Gaussian graphical models, that is, networks of partial correlation coefficients.

of the existential shame dimension, since guilt according to Tangney et al. (1995) is related to adaptive social behavior responses, increased empathy, prosocial, and reparative behavior. However, it is important to note that cognitive shame (an adaptive dimension) was related to both "shamefree guilt" and "guilt-free shame." We argue that the moderate correlation with "shame-free guilt" may be due to similarities in the conceptualization and the item content of the guilt scale underlying the TOSCA-3 and the cognitive shame scale in the SHAME. For example, items are composed of mostly social situations such as interpersonal interactions at work.

Previous research highlighted the association of shame with several mental health issues (e.g., Adamczyk, 2017). Our results support this body of literature, with shame proneness as represented by the SHAME total score being particularly strongly related to psychopathology. This connection is mainly due to the strong association of existential 


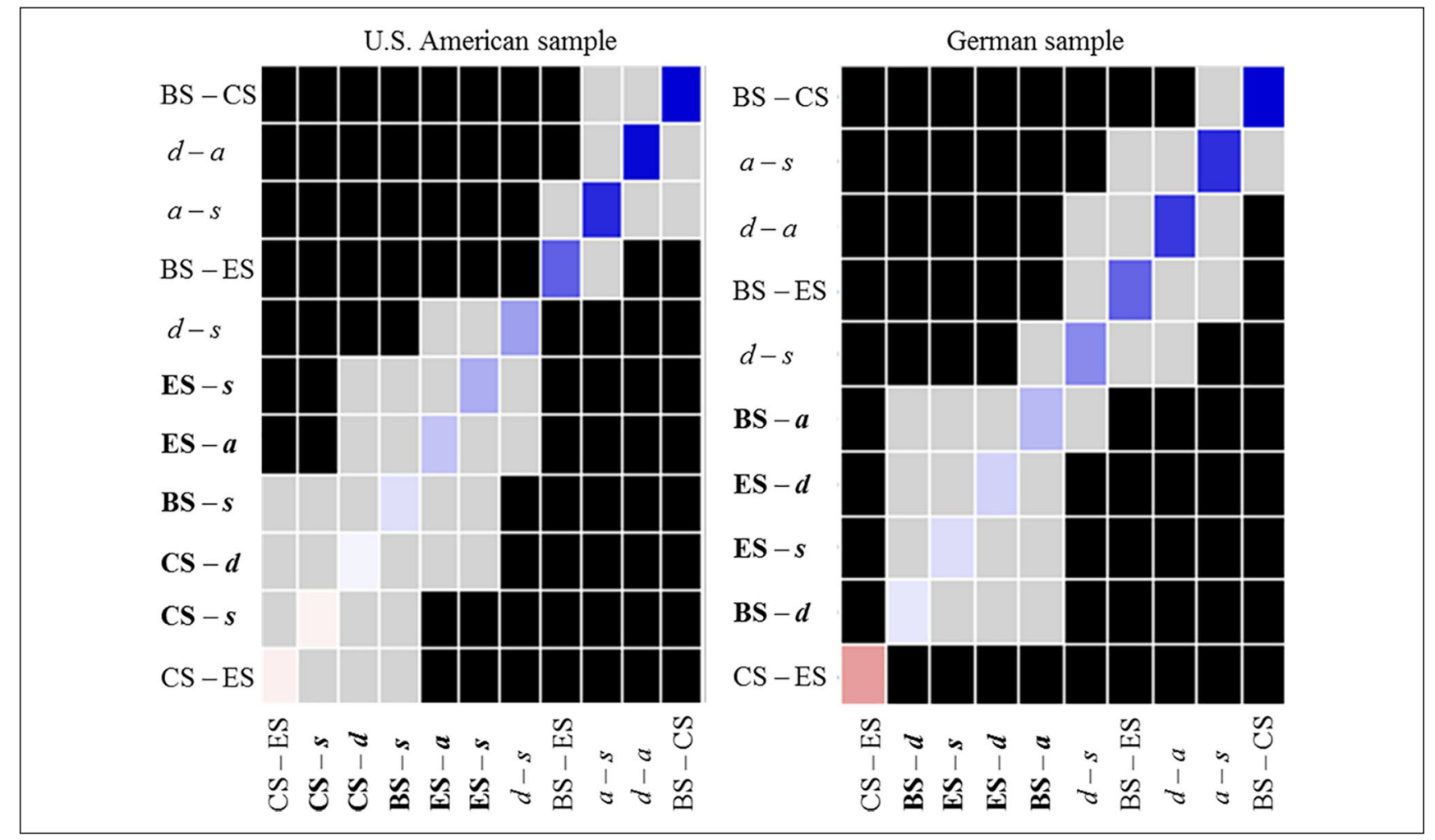

Figure 3. Difference tests between edge-weights in community samples.

Note. BS = bodily shame; CS = cognitive shame; ES = existential shame and psychopathology assessed with Brief Symptom Inventory; a = anxiety; $\mathrm{d}=$ depression; $\mathrm{s}=$ somatization (in Italics). Bootstrapped difference tests $(\alpha=.05)$ between nonzero edge-weights for shame proneness facets assessed with Shame Assessment for Multifarious Expressions of Shame. Edges connecting shame proneness and psychopathology are in bold face. Black boxes indicate significant differences between edge-weights, gray boxes indicate no significant difference. The first row in each graph displays the strongest edge-weight of the corresponding network model, the following rows are sorted in descending order.

\begin{tabular}{|c|c|c|c|c|c|c|c|c|c|c|c|c|c|}
\hline & \multicolumn{4}{|c|}{$\begin{array}{l}\text { U.S. American } \\
\text { women }\end{array}$} & & \multicolumn{3}{|c|}{ German women } & & \multicolumn{4}{|c|}{ Clinical sample } \\
\hline BS - CS & & & & & BS - CS & & & & ES - $g_{S i}$ & & & & \\
\hline $\mathrm{ES}-g s i$ & & & & & BS-ES & & & & $\mathrm{BS}-\mathrm{CS}$ & & & & \\
\hline BS - ES & & & & & & & & & BS - ES & & & & \\
\hline BS - $g s i$ & & & & & CS - ES & & & & BS - gsi & & & & \\
\hline & $\begin{array}{l}\tilde{\hat{b}} \\
\dot{0} \\
\dot{\alpha}\end{array}$ & 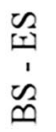 & 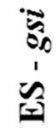 & $\begin{array}{l}U^{2} \\
\dot{1} \\
\text { ñ }\end{array}$ & & 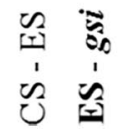 & 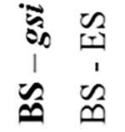 & $\begin{array}{l}\tilde{y} \\
1 \\
\tilde{1}\end{array}$ & & $\begin{array}{l}\tilde{\hat{\sigma}} \\
1 \\
\tilde{\omega}\end{array}$ & $\begin{array}{l}\text { त् } \\
\text { in } \\
\text { nी }\end{array}$ & $\begin{array}{l}y_{3} \\
1 \\
\text { ñ }\end{array}$ & 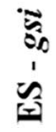 \\
\hline
\end{tabular}

Figure 4. Difference tests between edge-weights in female subsamples.

Note. BS = bodily shame; CS = cognitive shame; ES = existential shame and psychopathology assessed Brief Symptom Inventory; gsi = general severity index (in Italics). Bootstrapped difference tests $(\alpha=.05)$ between nonzero edge-weights for shame proneness facets assessed with Shame Assessment for Multifarious Expressions of Shame. Edges connecting shame proneness and psychopathology are in bold face. Black boxes indicate significant differences between edge-weights, gray boxes indicate no significant difference. The first row in each graph displays the strongest edge-weight of the corresponding network model, the following rows are sorted in descending order. 
shame with psychopathology. The potentially adaptive dimensions of shame (bodily and cognitive shame) did not show unique positive relations to psychopathology, which may be seen as further evidence for the multifaceted character of shame proneness.

Our results also show differentiated associations between the different dimensions of the SHAME and aggression. Previous research has highlighted relevant associations between shame and aggression (Thomaes, Stegge, Olthof, Bushman, \& Nezlek, 2011; Velotti et al., 2014; Velotti et al., 2017), especially with respect to interpersonal aggression including hostile behavior (Scott et al., 2015; Tignor \& Colvin, 2017) and anger (e.g., Stuewig, Tangney, Heigel, Harty, \& McCloskey, 2010; Tangney et al., 1996). Anger, for example, has been investigated as a reaction against the violation of self-esteem by feeling ashamed (Stuewig et. al., 2010; Tangney et al., 1996), and as an undifferentiated negative emotional reaction to shame (Thomaes et al., 2011). Results from bifactor model analyses revealed significant but only moderate relations between the total shame score and aggression, especially with respect to the subscales of anger and hostility. Looking at the different dimensions of shame proneness, the relation pattern seems to highlight the potentially adaptive and maladaptive aspects of this emotion. Results highlight the dimensions of bodily and cognitive shame as potentially adaptive shame aspects by showing negative relations to anger and hostility. On the contrary, existential shame revealed unique positive relations with all investigated facets of aggression. Our results are in line with previous research that was mainly concerned with the maladaptive side of shame showing relations to hostility and anger.

Furthermore, as shame often comes along with a feeling of helplessness, and decreased self-control (Catarino \& Gilbert, 2016; Patock-Peckham et al., 2018) we wanted to be sure that the SHAME discriminated between shame proneness and low self-control. Discriminant validity was supported by low negative associations between shame and self-control, with the highest negative association provided by existential shame.

Comparing results for the SHAME with results for the TOSCA-3 (Tangney et al., 2000) highlighted the maladaptive nature of shame as assessed with the TOSCA-3. For example, shame as assessed with the TOSCA-3 provided strong connections to psychopathology, aggression, and low self-control. This is in line with findings for the recently validated adolescent version of TOSCA (Tangney, Wagner, Gavlas, \& Gramzow, 1991) also presenting connections of shame with psychopathology and aggression (Watson, Gomez, \& Gullone, 2017). In contrast, the SHAME provides an opportunity for measuring shame proneness as a multidimensional construct including adaptive and maladaptive aspects, which should therefore be considered separately.
Furthermore, results from network analyses provided a first insight into differences concerning the SHAME dimensions with respect to culture and mental health. On the one hand, our results highlight the existential shame dimension as the core maladaptive aspect of shame proneness, with strong connections to psychopathology in each investigated sample. Nevertheless, the relation between existential shame and psychopathology was particularly pronounced in the clinical sample, which emphasizes its detrimental effects especially for participants with mental health problems. Additionally, it is important to note that the role of existential shame for psychopathological symptoms was also descriptively more pronounced in the female subsamples as compared with the mixed-sex samples. On the other hand, when investigating the connections of shame proneness and psychopathology in the community samples, a pattern of potential cultural differences in maladaptive shame occurred. A relation between existential shame and anxiety was only found in the U.S. American sample, whereas a relation between existential shame and depression was only found in the German sample. This could indicate a cultural difference in dealing with maladaptive shame.

Concerning the female subsamples, positive associations for bodily shame and psychopathology appeared only in the German subsample as well as in the clinical sample, but there was no significant association in the U.S. American sample. As the clinical group was also recruited in Germany, this may be more of a cultural difference. Our results highlight previous findings of the connection between shame proneness and psychopathology in nonclinical (Muris et al., 2015) and clinical samples (Adamczyk, 2017; Andrews et al., 2000; Brown et al., 2009; Castilho et al., 2017; Duarte et al., 2017). Additionally, they also provide some insights into potential differences in associations of shame facets with psychopathology concerning cultural and gender differences as well as differences in mental health status. Nevertheless, interpretations need to be made with care as so far differences between the estimated network models of the investigated groups could not be tested for significance due to, inter alia, sample size reasons.

\section{Limitations and Future Directions}

Although the community samples were sufficient in sample size, larger clinical samples with different mental disorders and a higher number of male patients would be necessary to investigate the relation between shame proneness and psychopathology more thoroughly. In particular, the network analyses would benefit from larger samples to increase stability, make it easier to interpret and more comparable statistically. Network analyses have been controversially discussed recently (e.g., Forbes, Wright, Markon, \& Krueger, 2017; see also Borsboom, Robinaugh, The Psychosystems Group, Rhemtulla, \& Cramer, 2018), especially with respect 
to the replicability of psychopathology networks. To meet these concerns, we used the extra conservative strategy of regularization in the present research. In a similar vein, future research interested in bifactor model analyses for testing construct validity may consider to include ancillary indices of the bifactor model beforehand (Reise et al., 2013; Rodriguez et al., 2016; Stucky et al., 2013) in order to establish indicators of dimensionality and reliability.

Additionally, the mean values for existential shame were rather low, even for the clinical sample. As we conceptualized existential shame as a maladaptive dimension, lower mean values were expected within the community samples. Since the clinical sample included outpatients with a moderate to high level of functioning, further studies are necessary to investigate mean-levels and interrelations to related constructs in a more impaired clinical group.

Another relevant question is the impact of shame proneness dimensions in everyday life as well as its relation to (adaptive and maladaptive) behavior responses. Due to the well-known far-reaching and manifold impact of shame proneness on behavior, social functioning, and psychopathology, assessing different aspects of shame in one instrument may add an important source of information to better understand adaptive and maladaptive consequences of this emotion. However, the current results are limited as we did not examine actual behavioral responses or important life outcomes. In future research, it might be interesting to assess psychopathological symptoms using clinical interviews for example, which could provide more information than self-reports. Furthermore, research might benefit from investigating particular adaptive life outcomes, such as life satisfaction or occupational success, to emphasize the adaptive role of bodily and cognitive dimensions of shame.

In this regard, we argued that there may be individual differences in the importance of each of the shame dimensions on life functioning. However, as we were unable to test this assumption, future research might want to investigate whether specific shame profiles are of major importance in the functioning of a person.

To gain more information about the importance of distinguishing between adaptive and maladaptive aspects of shame, it would be of great interest to expand the nomological network of shame by further investigating associations with empathy, interpersonal skills, and emotion regulation, for example. Especially interesting would be to also investigate the connection between shame proneness and other self-reflexive and social emotions such as guilt, pride, and envy, where more research is needed. Especially understanding maladaptive shame an investigation of the association to self-critical rumination would be of high interest. Both constructs are connected and related to several mental disorders, for example, BPD (Smart, Peters, \& Baer, 2016) and may be important for enduring improvement of mental health issues.
Concerning the clinical potential of the SHAME, longterm changes in relation to the dimensions of shame proneness could be of interest, especially with respect to reducing existential shame through psychotherapeutic interventions.

\section{Conclusion}

Most of the established instruments assessing shame focus on the maladaptive dimension of this emotion. The current work introduced a new valid instrument to assess adaptive and maladaptive dimensions of shame proneness. The SHAME assessment measure successfully met invariance criteria for U.S. American and German community samples. Convergent and discriminant validity was established through distinct associations between the different dimensions of the SHAME and associations with similar and dissimilar constructs. The SHAME assessment measure allows for a deeper and more differentiated insight into associations between shame proneness and psychopathology on the one hand and social functioning on the other.

\section{Authors' Note}

Katrin Rentzsch is also affiliated with Victoria University of Wellington, New Zealand.

\section{Declaration of Conflicting Interests}

The author(s) declared no potential conflicts of interest with respect to the research, authorship, and/or publication of this article.

\section{Funding}

The author(s) received no financial support for the research, authorship, and/or publication of this article.

\section{Notes}

1. Results from a Monte Carlo simulation study revealed a power of .78 to detect a lack of invariance for $25 \%$ of the items with a difference in factor loadings of .25 between the U.S. American and the German sample in the present study (see also Meade, Johnson, \& Braddy, 2008, for simulations of various levels of lack of invariance).

2. For reliable interpretation, the stability parameter $\operatorname{CS}(r=.7)$ should be at least larger than .25 and preferably larger .50 (Epskamp et al., 2017). According to Epskamp et al. (2017), centrality indices of nodes should not be interpreted if the stability parameter $\operatorname{CS}(r=.7)$ is smaller than .25 .

3. Based on regularization, only a small number of edgeweights are used to explain covariation, while edge-weights close to zero are dropped from network models (Costantini et al., 2015).

\section{Supplemental Material}

Supplemental material for this article is available online. 


\section{References}

Adamczyk, A. O. (2017). Shame, guilt and psychopathologytransdiagnostic approach. Journal of Education, Health and Sport, 7, 420-434. doi:10.5281/zenodo.495759

Andrews, B., Brewin, C. R., Rose, S., \& Kirk, M. (2000). Predicting PTSD symptoms in victims of violent crime: The role of shame, anger, and childhood abuse. Journal of Abnormal Psychology, 109, 69-73. doi:10.1037/0021-843X.109.1.69

Andrews, B., Qian, M., \& Valentine, J. D. (2002). Predicting depressive symptoms with a new measure of shame: The Experience of Shame Scale. British Journal of Clinical Psychology, 41, 29-42. doi:10.1348/014466502163778

Arimitsu, K. (2006). Guilt, shame/embarrassment, and empathy. Japanese Journal of Psychology, 77, 97-104. doi:10.4992/ jjpsy.77.97

Averill, P. M., Diefenbach, G. J., Stanley, M. A., Breckenridge, J. K., \& Lusby, B. (2002). Assessment of shame and guilt in a psychiatric sample: A comparison of two measures. Personality and Individual Differences, 32, 1365-1376. doi:10.1016/S0191-8869(01)00124-6

Barrett, K. C. (1998). A functionalist perspective to the development of emotions. In M. F. Mascolo \& S. Griffin (Eds.), What develops in emotional development? (pp. 109-133). New York, NY: Springer Science + Business Media.

Black, R. S. A., Curran, D., \& Dyer, K. F. W. (2013). The impact of shame on the therapeutic alliance and intimate relationships. Journal of Clinical Psychology, 69, 646-654. doi:10.1002/jclp.21959

Blum, A. (2008). Shame and guilt, misconceptions and controversies: A critical review of the literature. Traumatology, 14, 91-102. doi:10.1177/1534765608321070

Borsboom, D., \& Robinaugh, D. J., The Psychosystems Group, Rhemtulla, M., \& Cramer, A. O. J. (2018). Robustness and replicability of psychopathology networks. World Psychiatry, 17, 143-144. doi:10.1002/wps.20515

Brown, M. Z., Linehan, M. M., Comtois, K. A., Murray, A., \& Chapman, A. L. (2009). Shame as a prospective predictor of self-inflicted injury in borderline personality disorder: A multi-modal analysis. Behaviour Research and Therapy, 47, 815-822. doi:10.1016/j.brat.2009.06.008

Buhrmester, M., Kwang, T., \& Gosling, S. D. (2011). Amazon's Mechanical Turk: A new source of inexpensive, yet highquality, data? Perspectives on Psychological Science, 6, 3-5. doi:10.1177/1745691610393980

Buss, A. H., \& Perry, M. (1992). The Aggression Questionnaire. Journal of Personality and Social Psychology, 63, 452-459. doi:10.1037/0022-3514.63.3.452

Castilho, P., Pinto-Gouveia, J., \& Duarte, J. (2017). Two forms of self-criticism mediate differently the shame-psychopathological symptoms link. Psychology and Psychotherapy: Theory, Research and Practice, 90, 44-54. doi:10.1111/papt.12094

Catarino, F., \& Gilbert, P. (2016, June). The relationship between body image and weight-related shame and loss of control of eating in participants of a weight management programme. Poster presented at the European Obesity Summit (EOS), Gothenburg, Sweden. Abstract retrieved from https:/www .karger.com/Article/Abstract/446744

Chen, F. F., Hayes, A., Carver, C. S., Laurenceau, J. P., \& Zhang, Z. (2012). Modeling general and specific variance in mul- tifaceted constructs: A comparison of the bifactor model to other approaches. Journal of Personality, 80, 219-251. doi:10.1111/j.1467-6494.2011.00739.x

Chen, F. F., West, S. G., \& Sousa, K. H. (2006). A comparison of bifactor and second-order models of quality of life. Multivariate Behavioral Research, 41, 189-225. doi:10.1207/ s15327906mbr4102 5

Chen, J., \& Chen, Z. (2008). Extended Bayesian information criteria for model selection with large model spaces. Biometrika, 95, 759-771. doi:10.1093/biomet/asn034

Cherry, M. G., Taylor, P. J., Brown, S. L., Rigby, J. W., \& Sellwood, W. (2017). Guilt, shame and expressed emotion in carers of people with long-term mental health difficulties: A systematic review. Psychiatry Research, 249, 139-151. doi:10.1016/j.psychres.2016.12.056

Cheung, G. W., \& Rensvold, R. B. (2002). Evaluating goodness-of-fit indexes for testing measurement invariance. Structural Equation Modeling, 9, 233-255. doi:10.1207/ S15328007SEM0902 5

Cohen, T. R., Wolf, S. T., Panter, A. T., \& Insko, C. A. (2011). Introducing the GASP scale: A new measure of guilt and shame proneness. Journal of Personality and Social Psychology, 100, 947-966. doi:10.1037/a0022641

Costantini, G., Epskamp, S., Borsboom, D., Perugini, M., Mõttus, R., Waldorp, L. J., \& Cramer, A. O. (2015). State of the aRt personality research: A tutorial on network analysis of personality data in R. Journal of Research in Personality, 54, 13-29. doi:10.1016/j.jrp.2014.07.003

Cuthbert, B. N., \& Insel, T. R. (2013). Toward the future of psychiatric diagnosis: The seven pillars of RDoC. BMC Medicine, 11, 126. doi:10.1186/1741-7015-11-126

de Hooge, I. E. (2013). Moral emotions and prosocial behaviour: It may be time to change our view of shame and guilt. In $\mathrm{C}$. Mohiyeddini, M. Eysenck, \& S. Bauer (Eds.), Handbook of psychology of emotions: Recent theoretical perspectives and novel empirical findings (Vol. 2, pp. 255-276). Hauppauge, NY: Nova Science.

de Hooge, I. E., Zeelenberg, M., \& Breugelmans, S. M. (2010). Restore and protect motivations following shame. Cognition and Emotion, 24, 111-127. doi:10.1080/02699930802584466

de Hooge, I. E., Zeelenberg, M., \& Breugelmans, S. M. (2011). Self-conscious emotions and social functioning. In I. Nyklíček, A. Vingerhoets, \& M. Zeelenberg (Eds.), Emotion regulation and well-being (pp. 197-210). New York, NY: Springer Science + Business Media.

Deonna, J. A., Rodogno, R., \& Teroni, F. (2012). In defense of shame: The faces of an emotion. New York, NY: Oxford University Press.

Derogatis, L. R. (2000). The Brief Symptom Inventory-18 (BSI18): Administration, scoring and procedures manual. Minneapolis, MN: National Computer Systems.

Dorahy, M. J., McKendry, H., Scott, A., Yogeeswaran, K., Martens, A., \& Hanna, D. (2017). Reactive dissociative experiences in response to acute increases in shame feelings. Behaviour Research and Therapy, 89, 75-85. doi:10.1016/j.brat.2016.11.007

Dost, A., \& Yagmurlu, B. (2008). Are constructiveness and destructiveness essential features of guilt and shame feelings respectively? Journal for the Theory of Social Behaviour, 38, 109-129. doi:10.1111/j.1468-5914.2008.00362.x 
Duarte, C., Pinto-Gouveia, J., \& Stubbs, R. (2017). The prospective associations between bullying experiences, body image shame and disordered eating in a sample of adolescent girls. Personality and Individual Differences, 116, 319-325. doi:10.1016/j.paid.2017.05.003

Ekman, P. (1972). Universal and cultural differences in facial expressions of emotion. In J. R. Cole (Ed.), Nebraska symposium on motivation, 1971 (pp. 207-283). Lincoln: University of Nebraska Press.

Epskamp, S., Borsboom, D., \& Fried, E. I. (2017). Estimating psychological networks and their accuracy: A tutorial paper. Behavior Research Methods, 50, 195-212. doi:10.3758/ s13428-017-0862-1

Epskamp, S., Cramer, A. O., Waldorp, L. J., Schmittmann, V. D., \& Borsboom, D. (2012). qgraph: Network visualizations of relationships in psychometric data. Journal of Statistical Software, 48, 1-18. doi:10.18637/jss.v048.i04

First, M. B., Spitzer, R. L., Williams, J. B. W., \& Gibbon, M. (1997). Structured Clinical Interview for DSM-IV Axis II Personality Disorders (SCID-II) user's guide and interview. Washington, DC: American Psychiatric Press.

Forbes, M. K., Wright, A. G. C., Markon, K. E., \& Krueger, R. F. (2017). Further evidence that psychopathology networks have limited replicability and utility: Response to Borsboom et al. (2017) and Steinley et al. (2017). Journal of Abnormal Psychology, 126, 1011-1016. doi:10.1037/abn0000313

Fydrich, T., Renneberg, B., Schmitz, B., \& Wittchen, H.-U. (1997). Structured Clinical Interview for DSM-IV Axis II Personality Disorders (SCID-II). Göttingen, Germany: Hogrefe

Garcia, A. F., Acosta, M., Pirani, S., Edwards, D., \& Osman, A. (2017). Factor structure, factorial invariance, and validity of the Multidimensional Shame-Related Response Inventory-21 (MSRI-21). Journal of Counseling Psychology, 64, 233-246. doi:10.1037/cou0000192

Gausel, N., Vignoles, V. L., \& Leach, C. W. (2016). Resolving the paradox of shame: Differentiating among specific appraisal-feeling combinations explains pro-social and selfdefensive motivation. Motivation and Emotion, 40, 118-139. doi:10.1007/s11031-015-9513-y

Gilbert, P. (1998). What is shame? Some core issues and controversies. In P. Gilbert \& B. Andrews (Eds.) Shame: Interpersonal behavior, psychopathology and culture (pp. 3-36). New York, NY: Oxford University Press.

Gilbert, P., McEwan, K., Irons, C., Bhundia, R., Christie, R., Broomhead, C., \& Rockliff, H. (2010). Self-harm in a mixed clinical population: The roles of self-criticism, shame, and social rank. British Journal of Clinical Psychology, 49, 563576. doi:10.1348/014466509x479771

Goss, K., \& Allan, S. (2009). Shame, pride and eating disorders. Clinical Psychology \& Psychotherapy, 16, 303-316. doi:10.1002/cpp.627

Gross, J. J. (2001). Emotion regulation in adulthood: Timing is everything. Current Directions in Psychological Science, 10, 214-219. doi:10.1111/1467-8721.00152

Guimón, J., Las Hayas, C., Guillén, V., Boyra, A., \& GonzálezPinto, A. (2007). Shame, sensitivity to punishment and psychiatric disorders. European Journal of Psychiatry, 21, 124-133. doi:10.4321/s0213-61632007000200004
Harned, M. S., Korslund, K. E., \& Linehan, M. M. (2014). A pilot randomized controlled trial of Dialectical Behavior Therapy with and without the Dialectical Behavior Therapy Prolonged Exposure protocol for suicidal and self-injuring women with borderline personality disorder and PTSD. Behaviour Research and Therapy, 55, 7-17. doi:10.1016/j. brat.2014.01.008

Hilgers, M. (2006). Shame: Faces of an affect. Göttingen, Germany: Vandenhoeck \& Ruprecht.

Iannaccone, M., D’Olimpio, F., Cella, S., \& Cotrufo, P. (2016). Self-esteem, body shame and eating disorder risk in obese and normal weight adolescents: A mediation model. Eating Behaviors, 21, 80-83. doi:10.1016/j.eatbeh.2015.12.010

Joireman, J. (2004). Empathy and the self-absorption paradox II: Self-rumination and self-reflection as mediators between shame, guilt, and empathy. Self and Identity, 3, 225-238. doi: $10.1080 / 13576500444000038$

Keith, L., Gillanders, D., \& Simpson, S. (2009). An exploration of the main sources of shame in an eating-disordered population. Clinical Psychology \& Psychotherapy, 16, 317-327. doi:10.1002/cpp.629

Kim, S., Thibodeau, R., \& Jorgensen, R. S. (2011). Shame, guilt, and depressive symptoms: A meta-analytic review. Psychological Bulletin, 137, 68-96. doi:10.1037/a0021466

Lauritzen, S. L. (1996). Graphical models. New York, NY: Oxford University Press.

Lazarus, R. S. (1991). Emotion and adaptation. New York, NY: Oxford University Press.

Lester, D. (1998). The association of shame and guilt with suicidality. Journal of Social Psychology, 138, 535-536. doi:10.1080/00224549809600407

Lewis, H. B. (1971). Shame and guilt in neurosis. New York, NY: International Universities Press.

Lewis, M. (2008). Self-conscious emotions: Embarrassment, pride, shame, and guilt. In M. Lewis, J. M. Haviland-Jones, \& L. F. Barrett (Eds.), Handbook of emotions (3rd ed., pp. 742756). New York, NY: Guilford Press.

Meade, A. W., Johnson, E. C., \& Braddy, P. W. (2008). Power and sensitivity of alternative fit indices in tests of measurement invariance. Journal of Applied Psychology, 93, 568-592. doi:10.1037/0021-9010.93.3.568

Meredith, W. (1993). Measurement invariance, factor analysis and factorial invariance. Psychometrika, 58, 525-543. doi: $10.1007 /$ bf02294825

Mills, R. S., Hastings, P. D., Serbin, L. A., Stack, D. M., Abela, J. R., Arbeau, K. A., \& Lall, D. I. (2015). Depressogenic thinking and shame proneness in the development of internalizing problems. Child Psychiatry \& Human Development, 46, $194-$ 208. doi:10.1007/s10578-013-0416-4

Muris, P., Meesters, C., Bouwman, L., \& Notermans, S. (2015). Relations among behavioral inhibition, shame-and guiltproneness, and anxiety disorders symptoms in non-clinical children. Child Psychiatry \& Human Development, 46, 209216. doi:10.1007/s10578-014-0457-3

Murphy, S. A., \& Kiffin-Petersen, S. (2017). The exposed self: A multilevel model of shame and ethical behavior. Journal of Business Ethics, 141, 657-675. doi:10.1007/s10551-016$3185-8$ 
Muthén, L. K., \& Muthén, B. O. (2012). Mplus user's guide (7th ed.). Los Angeles, CA: Muthén \& Muthén.

Nazarov, A., Jetly, R., McNeely, H., Kiang, M., Lanius, R., \& McKinnon, M. (2015). Role of morality in the experience of guilt and shame within the armed forces. Acta Psychiatrica Scandinavica, 132, 4-19. doi:10.1111/acps.12406

Patock-Peckham, J. A., Canning, J. R., \& Leeman, R. F. (2018). Shame is bad and guilt is good: An examination of the impaired control over drinking pathway to alcohol use and related problems. Personality and Individual Differences, 121, 62-66. doi:10.1016/j.paid.2017.09.023

Peters, J. R., Geiger, P. J., Smart, L. M., \& Baer, R. A. (2014). Shame and borderline personality features: The potential mediating role of anger and anger rumination. Personality Disorders: Theory, Research, and Treatment, 5, 1-9. doi:10.1037/per0000022

Reise, S. P., Scheines, R., Widaman, K. F., \& Haviland, M. G. (2013). Multidimensionality and structural coefficient bias in structural equation modeling: A bifactor perspective. Educational and Psychological Measurement, 73, 5-26. doi:10.1177/0013164412449831

Rizvi, S. L., Brown, M. Z., Bohus, M., \& Linehan, M. M. (2011). The role of shame in the development and treatment of borderline personality disorder. In R. L. Dearing \& J. P. Tangney (Eds.), Shame in the therapy hour (pp. 237-260). Washington, DC: American Psychological Association.

Rodriguez, A., Reise, S. P., \& Haviland, M. G. (2016). Evaluating bifactor models: Calculating and interpreting statistical indices. Psychological Methods, 21, 137-150. doi:10.1037/met0000045

Rosenberg, E. L. (1998). Levels of analysis and the organization of affect. Review of General Psychology, 2, 247-270. doi:10.1037/1089-2680.2.3.247

Scheel, C. N., Bender, C., Tuschen-Caffier, B., Brodführer, A., Matthies, S., Hermann, C., . . . Jacob, G. A. (2014). Do patients with different mental disorders show specific aspects of shame? Psychiatry Research, 220, 490-495. doi:10.1016/j. psychres.2014.07.062

Scheel, C. N., Bender, C., Tuschen-Caffier, B., \& Jacob, G. A. (2013). SHAME-Entwicklung eines Fragebogens zur Erfassung positiver und negativer Aspekte von Scham [SHAMEDevelopment of a questionnaire capturing positive and negative aspects of shame]. Zeitschrift für Klinische Psychologie und Psychotherapie, 42, 280-290. doi:10.1026/1616-3443/a000228

Scheel, C. N., \& Rentzsch, K. (2018). Assessment of different dimensions of shame proneness: Validation of the SHAME. Retrieved from https://osf.io/g6vur

Scherer, K. R. (1984). On the nature and function of emotion: A component process approach. In K. R. Scherer \& P. Ekman (Eds.), Approaches to emotion (pp. 293-318). Hillsdale, NJ: Lawrence Erlbaum.

Schoenleber, M., Berenbaum, H., \& Motl, R. (2014). Shamerelated functions of and motivations for self-injurious behavior. Personality Disorders: Theory, Research, and Treatment, 5, 204-211. doi:10.1037/per0000035

Scott, L. N., Stepp, S. D., Hallquist, M. N., Whalen, D. J., Wright, A. G., \& Pilkonis, P. A. (2015). Daily shame and hostile irritability in adolescent girls with borderline personality disorder symptoms. Personality Disorders: Theory, Research, and Treatment, 6, 53-63. doi:10.1037/per0000107
Simonds, L. M., John, M., Fife-Schaw, C., Willis, S., Taylor, H., Hand, H., . . W Winton, H. (2016). Development and validation of the Adolescent Shame-Proneness Scale. Psychological Assessment, 28, 549-562. doi:10.1037/pas0000206

Skårderud, F. (2007). Shame and pride in anorexia nervosa: A qualitative descriptive study. European Eating Disorders Review, 15, 81-97. doi:10.1002/erv.774

Smart, L. M., Peters, J. R., \& Baer, R. A. (2016). Development and validation of a measure of self-critical rumination. Assessment, 23, 321-332. doi:10.1177/1073191115573300

Spitzer, R. L., Williams, J. B., Gibbon, M., \& First, M. B. (1992). The structured clinical interview for DSM-III-R (SCID). I: History, rationale, and description. Archives of General Psychiatry, 49, 624-629. doi:10.1001/archpsyc. 1992.01820080032005

Stucky, B. D., Thissen, D., \& Edelen, M. O. (2013). Using logistic approximations of marginal trace lines to develop short assessments. Applied Psychological Measurement, 37, 41-57. doi:10.1177/0146621612462759

Stuewig, J., Tangney, J. P., Kendall, S., Folk, J. B., Meyer, C. R., \& Dearing, R. L. (2015). Children's proneness to shame and guilt predict risky and illegal behaviors in young adulthood. Child Psychiatry \& Human Development, 46, 217-227. doi:10.1007/s10578-014-0467-1

Stuewig, J., Tangney, J. P., Heigel, C., Harty, L., \& McCloskey, L. (2010). Shaming, blaming, and maiming: Functional links among the moral emotions, externalization of blame, and aggression. Journal of Research in Personality, 44, 91-102. doi:10.1016/j.jrp.2009.12.005

Tangney, J. P., Baumeister, R. F., \& Boone, A. L. (2004). High self-control predicts good adjustment, less pathology, better grades, and interpersonal success. Journal of Personality, 72, 271-324. doi:10.1111/j.0022-3506.2004.00263.x

Tangney, J. P., Burggraf, S. A., \& Wagner, P. E. (1995). Shameproneness, guilt-proneness, and psychological symptoms. In J. P. Tangney \& K. W. Fischer (Eds.), Self-conscious emotions: The psychology of shame, guilt, embarrassment, and pride (pp. 343-367). New York, NY: Guilford Press.

Tangney, J. P., \& Dearing, R. L. (2002). Shame and guilt. New York, NY: Guilford Press.

Tangney, J. P., Dearing, R. L., Wagner, P. E., \& Gramzow, R. (2000). The Test of Self-Conscious Affect-3 (TOSCA-3). Fairfax, VA: George Mason University.

Tangney, J. P., Wagner, P., \& Gramzow, R. (1992). Proneness to shame, proneness to guilt, and psychopathology. Journal of Abnormal Psychology, 101, 469-478. doi:10.1037/0021843X.101.3.469

Tangney, J. P., Wagner, P. E., Hill-Barlow, D., Marschall, D. E., \& Gramzow, R. (1996). Relation of shame and guilt to constructive versus destructive responses to anger across the lifespan. Journal of Personality and Social Psychology, 70, 797-809. doi:10.1037/0022-3514.70.4.797

Tangney, J. P., Wagner, P., Gavlas, J., \& Gramzow, R. (1991). The Test of Self-Conscious Affect for Adolescents (TOSCA-A). Fairfax, VA: George Mason University.

Thomaes, S., Stegge, H., Olthof, T., Bushman, B. J., \& Nezlek, J. B. (2011). Turning shame inside-out: "Humiliated fury" in young adolescents. Emotion, 11, 786-793. doi:10.1037/ a0023403 
Tibshirani, R. (1996). Regression shrinkage and selection via the lasso. Journal of the Royal Statistical Society: Series B (Methodological), 58, 267-288.

Tignor, S. M., \& Colvin, C. R. (2017). The interpersonal adaptiveness of dispositional guilt and shame: A meta-analytic investigation. Journal of Personality, 85, 341-363. doi:10.1111/ jopy. 12244

Tracy, J. L., \& Matsumoto, D. (2008). The spontaneous expression of pride and shame: Evidence for biologically innate nonverbal displays. Proceedings of the National Academy of Sciences, 105, 11655-11660. doi:10.1073/ pnas.0802686105

Tracy, J. L., \& Robins, R. W. (2006). Appraisal antecedents of shame and guilt: Support for a theoretical model. Personality and Social Psychology Bulletin, 32, 1339-1351. doi:10.1177/0146167206290212
Velotti, P., Elison, J., \& Garofalo, C. (2014). Shame and aggression: Different trajectories and implications. Aggression and Violent Behavior, 19, 454-461. doi:10.1016/j.avb.2014.04.011

Velotti, P., Garofalo, C., Bottazzi, F., \& Caretti, V. (2017). Faces of shame: Implications for self-esteem, emotion regulation, aggression, and well-being. Journal of Psychology, 151, 171184. doi:10.1080/00223980.2016.1248809

Watson, S., Gomez, R., \& Gullone, E. (2017). The shame and guilt scales of the Test of Self-Conscious Affect-Adolescent (TOSCA-A): Factor structure, concurrent and discriminant validity, and measurement and structural invariance across ratings of males and females. Assessment, 24, 517-527. doi: $10.1177 / 1073191115608942$

Wittchen, H.-U., Wunderlich, U., Gruschwitz, S., \& Zaudig, M. (1997). Structured Clinical Interview for DSM-IV Axis I (SCID-I): Mental Disorders. Göttingen, Germany: Hogrefe. 